\title{
Rearing and display variables in sociability'
}

HARRY P. SHELLEY AND KERMIT T. HOYENGA

UNIVERSITY OF NEBRASIIA

The present experiments are concerned with an aspect of behavior which Lindzey et al (1965) have called sociability and defined as the time spent next to caged display animals in an open field. Two experiments are described: The second experiment replicates the unexpected findings of the first and in addition assesses the effects of species variation in the display animal. At weaning rats were caged singly or in groups of 8 or 9 and tested at 107 days (Experiment I) and 79 days (Experiment II). Sociability scores with a chick display, although significantly lower than for a rat display, are greater than for an empty cage. Although starting at approximately the same point, over a series of daily trials the socially isolated Ss spend more time next to the display animals whereas group reared Ss spend less time. The role of stimulus novelty and habituation, social motivation, social interaction, and genetic factors in sociability are discussed.

Lindzey et al (1965) have identified genetic differences in the sociability of mice. Sociability is defined as the time spent next to caged display animals in opposite corners of an open field. Two experiments were conducted. Experiment I tested the hypothesis that postweaning group living will result in higher sociability scores than post-weaning social isolation. When the results of Experiment I were significant but in the opposite direction from prediction, Experiment II was conducted to (1) verify the findings of Experiment $I$ and (2) study the effect of variation in the display animal, since the effects of variation will provide evidence as to the nature of the sociability response. A chick was selected as a second display animal since it had appropriate auditory and visual properties, was of a size for the apparatus, and yet differed from the rat in significant phylogenetic ways.

\section{Method}

Subjects and apparatus. Holtzman Sprague-Dawley rats were placed at weaning either singly or in groups of 8 or 9 in $38 \times 12 \times 12$ in. cages. Food and water consumption was ad lib. The Ss were 107 days (Experiment I) or 79 days old (Experiment II) at testing. To accommodate rats rather than mice the open field was enlarged to $48 \times 48$ in., the wall height increased to 12 in., and the four display cages enlarged to $8 \times 8 \times 8$ in.

Procedure. Following Lindzey et al a line was drawn on the floor $6 \mathrm{in}$. a way from the two exposed sides of the display cages. When a rat placed two feet inside the line he was judged adjacent to the cage. An observer with stop watches recorded the time spent adjacent to the display and empty cages. The observer also noted any freezing (lack of motion for more than $3 \mathrm{sec}$. when not adjacent to a cage). The only light source was a 40 watt bulb $48 \mathrm{in}$. above the center of the floor.

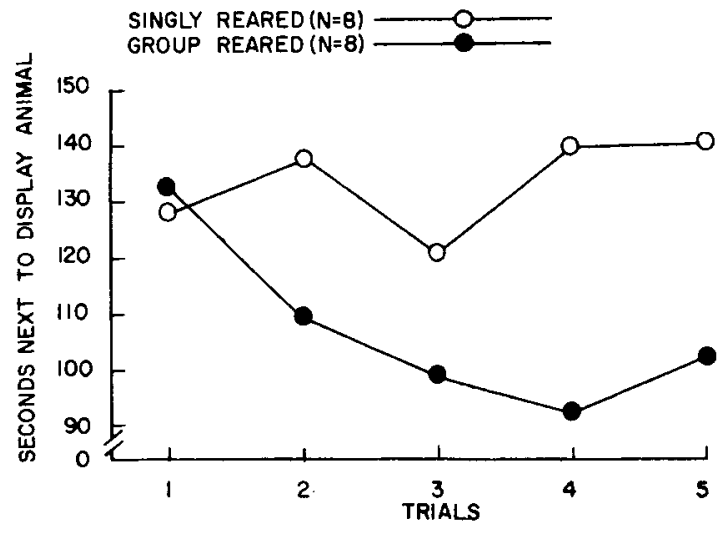

Fig. 1. Experiment I. Sociability as a function of social rearing conditions.

The display cages were placed in diagonally opposite corners and systematically rotated for each successive trial. $S$ was placed in the center of the open field and allowed to run freely for $5 \mathrm{~min}$. Each $\mathrm{S}$ was given a trial on each of 5 (Experiment I) or 6 (Experiment In consecutive days. In Experiment II a rat was used as the display for half of the Ss in each rearing condition; for the other half a 42 day old Hyline chick was used. Results

Experiment $I$. Analysis of variance of the data plotted in Fig. 1 indicates a significant rearing by trials interaction $(F=4.36, d f=4 / 56, p<.01)$ as well as a difference between rearing conditions $(F=25.06, d f=1 / 14, p<.01)$. Only trivial chance differences are found when the data on time next to the empty cages are analyzed.

Experiment II. Although rearing effects across all trials and all display conditions are not significant

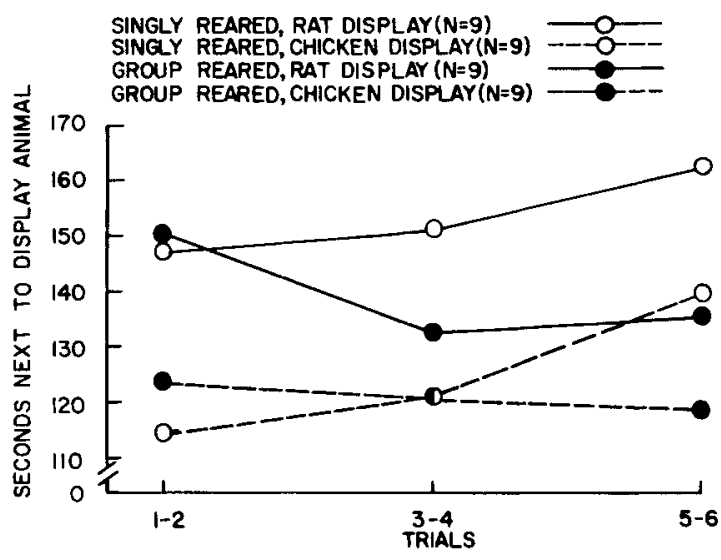

Fig. 2. Experiment II. Sociability as a function of social rearing conditions and display animal 
$(\mathrm{F}=\mathbf{2 . 1 2}, \mathrm{df}=1 / 32, \mathrm{p}>.05)$, the rearing by trials interaction is replicated (Fig. 2) and is of particular significance $(F=5.03, \mathrm{df}=2 / 64, \mathrm{p}<.01)$. The failure to replicate rearing effects is not particularly significant since inspection of Fig. 2 indicates that a significant rearing effect would result with additional trials. Initially time spent by the display rat does not differ as a function of rearing conditions, but over the trials the curves separate. Although the time values are significantly less than with a rat display (over all trials $(F=14.77, \mathrm{df}=1 / 32, \mathrm{p}<.01)$ the curves for the chick display condition are essentially parallel to those for the rat display, i.e., $F<1.00$ for the display by rearing by trials interaction). Again only trivial chance differences are found when the data on time next to the display cages are analyzed.

When the time next to the empty cages is summed over all trials and subtracted from the time next to the chicken display cages summed over all trials, 14 of the 18 remainders are positive (sign test, $n=18, p<.02$ ), i.e., the time spent next to the chick display is significantly greater than the time spent next to the empty cages.

Emotionality. In neither experiment was there a single instance of freezing; neither were there enough fecal boli to provide a measure of emotionality. Fear as it is usually measured in the open field was not a factor in Ss' behavior.

\section{Discussion}

Starting at approximately the same point, the socially isolated Ss spend increasing amounts of time adjacent to the display animal while the group reared Ss spend less and less time there. Although the absolute times are less, the curves for the chick display are essentially similar to those for the rat display. Chick or rat more time is spent by the display cages than by the empty cages.

Accounting for the findings requires consideration of the following, not necessarily exclusive, conditions:

1. Novel stimulus and habituation effects (Berlyne, 1960). Novel stimuli or complex stimuli have the property of receiving attention and directing investigative behavior. Berlyne's habituation hypothesis holds that repeated exposure to a stimulus reduces or eliminates the tendency of an organism to respond selectively to that stimulus. For the group reared Ss the display rats become identified quickly and attention is directed to other parts of the open field. For the socially isolated Ss, not accustomed to other animals in the environment, the open field is more quickly explored and the more novel elements, the display rats, receive more attention in sub- sequent trials. However, if novelty and habituation are the sole factors operating, the chick displays should receive more attention than the rat displays. Such is not the case.

2. Social motivation-deprivation effects. During the preweaning period social motives are acquired which are then deprived under social isolation rearing conditions. The effects of deprivation are masked in the early trials by exploration of the open field. As exploration is accomplished, more time is available for "socializing." The group reared Ss, whose social motives have not been deprived, quickly identify the display animal and then spend more time in exploring the more novel open field. Generalization effects may be used to account for the time spent next to the chick display. However, the assumption of social motives for the laboratory rat rest, at best, on shaky and meager grounds.

3. Interaction effects. Not only are the stimuli from an animate display varied and irregular but the display animal may also react to $S^{\prime} S$ behavior as well as $S$ reacting to the display's behavior. Such interaction does occur and resembles play-fighting including tactile contact since it is possible for one animal to bite at the other animal's toes through the wire mesh. To some extent similar interaction occurred with the chick display. However, it was more limited and occasional pecks by the chick would briefly drive Saway. Such differences in interaction may partially account for the lower sociability scores for the chick display.

4. Genetic effects. Although there are obvious problems in going from one species to another, the evidence that variations in sociability can be produced by variations in post-weaning rearing and the fact that sociability responses are made to the chick display indicate that whatever the genetic determinant it operates in a more general way. The problem is analogous to the imprinting situation. The following response is not a social response unless conditions are such as to make it social (Hess, 1959). Sociability behavior may be social only because the situation makes it so.

\section{References}

Berlyne, D. E. Conflict, arousal, and curiosity. New York: McGraw-Hill, 1960 .

Hess, E. The relationship between imprinting and motivation. In M. R. Jones (Ed.), Nebraska symposiums on motivation. LincoIn: University Nebraska Press, 1959, Pp. 44-77.

Lindzey, G., Winston, H. D., \& Roberts, L. E. Sociability, fearfulness, and genetic variation in the mouse. J. pers.soc. Psychol., 1965, 1, 642-645.

Note

1. This research was supported by N. I. M. H. Research Grant MH0703102. 